\title{
PENGARUH EKUITAS MEREK BERBASIS PELANGGAN TERHADAP KEPUASAN KONSUMEN MOBIL JENIS LOW COST GREEN CAR
}

\author{
Mohammad Soleh Soe'aidy, Adhitya Rahmat Taufiq, Andina Eka Mandasari \\ Universitas Siliwangi \\ Jl. Siliwangi No. 24, Tasikmalaya 46115, Indonesia \\ mochss@gmail.com
}

\begin{abstract}
Abstrak
Tujuan dari penelitian ini adalah untuk mengetahui bagaimana pengaruh dimensi ekuitas merek berbasis pelanggan (brand salience, brand performance, brand imagery, brand judgments, brand feelings, dan brand resonance) terhadap kepuasan konsumen mobil jenis Low Cost Green Car (LCGC) di Kota Tasikmalaya. Penelitian ini bersifat deskriptif dan empiris. Teknik pengumpulan data melalui penyebaran angket kepada 150 orang responden yang merupakan pengguna mobil jenis Low Cost Green Car (LCGC) dengan menggunakan teknik judgement sampling atau purposive sampling. Serta alat analisis yang digunakan adalah analisis jalur dimana enam dimensi CBBE menjadi variabel eksogen. Berdasarkan hasil analisis jalur, hanya 3 variabel ekuitas merek berbasis pelanggan yang berpengaruh terhadap kepuasan konsumen mobil jenis Low Cost Green Car (LCGC) di Kota Tasikmalaya, yaitu brand performance, brand imagery, dan brand feelings dimana variabel brand feelings yang paling berpengaruh.
\end{abstract}

Kata kunci : Ekuitas Merek, Kepuasan Konsumen, Low Cost Green Car

\begin{abstract}
The purpose of this research is to know how the influence of customer's brand equity dimension (brand salience, brand performance, brand imagery, brand judgments, brand feelings, and brand resonance) to consumer satisfaction of Low Cost Green Car (LCGC) in Tasikmalaya City. This research is descriptive and empirical. Data collection techniques through questionnaires to 150 respondents who are users of the car type Low Cost Green Car (LCGC) by using judgment sampling technique or purposive sampling. And the analytical tool used is path analysis where six dimensions CBBE become exogenous variable. Based on the result of path analysis, only 3 customer equity brand variables influence to consumer satisfaction of Low Cost Green Car (LCGC) in Tasikmalaya City, that is brand performance, brand imagery, and brand feelings where the most influential brand feelings variables.
\end{abstract}

Keywords: Brand Equity, Consumer Satisfaction, Low Cost Green Car

\section{PENDAHULUAN}

Industri otomotif Indonesia dituntut

untuk selalu berinovasi menciptakan

kendaraan yang murah dan hemat bahan

bakar karena adanya persaingan di

Kawasan Perdagangan Bebas (Free Trade

Area/FTA). Oleh karena itu, pemerintah

mengeluarkan kebijakan dan aturan mengenai mobil murah dan ramah lingkungan (Low Cost Green Car/LCGC).

Kemudian Kementerian Perindustrian (Kemenperin) Indonesia semakin mengukuhkan dengan mengeluarkan peraturan tentang Pengembangan Produksi

Kendaraan Bermotor Roda Empat yang Hemat Energi dan Harga Terjangkau. 
Mohammad, Aditya, Pengaruh Ekuitas Merek Berbasis...

Berdasarkan peraturan-peraturan pemerintah tersebut, kendaraan yang dikategorikan sebagai LCGC adalah mereka dengan mesin lebih kecil dari 1.200 cc, serta diesel dan semi-diesel mobil di bawah 1.500 cc yang dapat berjalan setidaknya 20 kilometer per liter.

Survey yang dilakukan Gaikindo memperlihatkan pertumbuhan market share kendaraan roda empat jenis LCGC termasuk ke dalam 3 jenis kendaraan roda empat yang paling diminati. Selain itu, pertumbuhan market share kendaraan jenis LCGC bersifat positif dibandingkan kendaraan roda empat yang termasuk dalam jenis $4 \times 2$ dan pick up/truck. Pada tahun awal kemunculannya yaitu tahun 2013, volume penjualan LCGC sebanyak 51.180 unit dengan market share sebesar $4,16 \%$ dari total penjualan kendaraan roda empat. Munculnya mobil harga terjangkau dan hemat energi (LGCG) di Indonesia sudah menguasai $13,8 \%$ dari total penjualan seluruh mobil penumpang dan kendaraan komersial di Indonesia (Kompas, 2014).

Tasikmalaya merupakan salah satu diantara kota-kota lain di Jawa Barat yang potensial untuk industri otomotif, dimana dengan melihat pertumbuhan yang pesat memungkinkan meningkatnya kebutuhan akan alat transportasi yang ada. Selama 2014 total penjualan seluruh merek dan kelas kendaraan roda empat nasional mencapai 1.208.028 unit dan sebesar 19,31\% diantaranya merupakan kontribusi Jawa Barat (Gaikindo, 2015).

Keunggulan mobil LCGC adalah harga yang terhitung murah, irit bahan bakar, dan ramah lingkungan. Dengan harga yang murah maka terdapat beberapa hal yang dibatasi. Namun walaupun mobil LCGC memiliki kekurangan lebih banyak dibandingkan keunggulannya, market share mobil LCGC setiap tahun terus mengalami peningkatan. Karena itu penting bagi produsen untuk mengetahui ekuitas merek (brand equity) produknya dengan melakukan riset terhadap elemenelemen ekuitas merek. Keller mendefinisikan ekuitas merek yang lebih berfokus pada perspektif perilaku konsumen. Hal ini bertolak belakang dengan penelitian (Puspita, 2014) bahwa variabel keutamaan merek, kinerja merek, citra merek tidak berpengaruh terhadap minat beli produk.

Dalam (Fandy, 2006) Keller menjabarkan aset brand equity yang berkontribusi pada proses implementasi dan membutuhkan enam building blocks utama yang dikenal dengan istilah Customer-Based Brand Equity (CBBE), yaitu: Brand salience, Brand performance, Brand imagery, Brand judgments, Brand feelings, dan Brand resonance. Peran brand equity yang sangat penting menyebabkan pengkajian brand equity 
yang mendalam pada sebuah merek produk dinilai sangat perlu untuk dilakukan. Selain itu untuk dapat terus mengembangkan dan memperbaiki kinerja produk, sangat perlu untuk mengetahui sudah sejauh mana tingkat kepuasan konsumen dari produk perusahaan, karena semakin tinggi tingkat kepuasan individu yang mengkonsumsi barang atau jasa maka besar kemungkinan bahwa individu tersebut akan setia atau loyal bahkan merekomendasikan produk tersebut pada orang lain. Hal ini sangatlah penting bagi kelangsungan bisnis untuk jangka panjang.

Metode yang digunakan dalam penelitian ini adalah dengan menggunakan metode penelitian survei. Populasi dalam penelitian ini adalah konsumen mobil jenis LCGC yang berada di kota Tasikmalaya. Teknik sampling yang digunakan adalah purposive sampling dimana penarikan sampel didasarkan pada pertimbangan pribadi peneliti yang bersangkutan (Sugiama, 2008). Pada sampling ini peneliti berupaya mencari keyakinan terlebih dahulu bahwa individu yang dipilih sebagai sampel merupakan individu yang tepat yaitu orang-orang yang menggunakan mobil jenis LCGC.

Penentuan ukuran sampel yang dilakukan dengan menggunakan cara interval taksiran karena jumlah populasi sangat banyak dan tidak diketahui secara pasti seberapa besarnya. Untuk mengetahui seberapa banyak sampel yang mewakili populasi, maka digunakan perhitungan dengan rumus Husain, (Husain, 2002). Berdasarkan perhitungan, maka sampel minimum yang harus diambil sebesar 96,04 responden. Dalam penelitian ini penentuan ukuran sampel didasarkan pada pendapat Hair (Hair, 1995) yaitu untuk penelitian survey ukuran minimal sampel adalah 100. Oleh karena itu, untuk meningkatkan ketelitian, maka sampel yang diambil dalam penelitian ini adalah sebanyak 150 responden karena jika menggunakan jumlah sampel minimum dianggap terlalu sedikit.

Untuk mengetahui pengaruh ekuitas merek berbasis pelanggan $\{$ Brand Salience $\left(\mathrm{X}_{1}\right)$, Brand Performance $\left(\mathrm{X}_{2}\right)$, Brand Imagery $\left(\mathrm{X}_{3}\right)$, Brand Judgments $\left(\mathrm{X}_{4}\right)$, Brand Feelings $\left(\mathrm{X}_{5}\right)$, Brand Resonance $\left.\left(\mathrm{X}_{6}\right)\right\}$ terhadap Kepuasan Konsumen (Y), digunakan metode analisis jalur. Setelah melalui uji validitas dan reliabilitas kuesioner didapatkan gambar diagram jalur terdiri dari enam buah variabel eksogen (X1, X2, X3, X4, dan X5) dan sebuah variabel endogen (Y) yaitu sebagai berikut. 


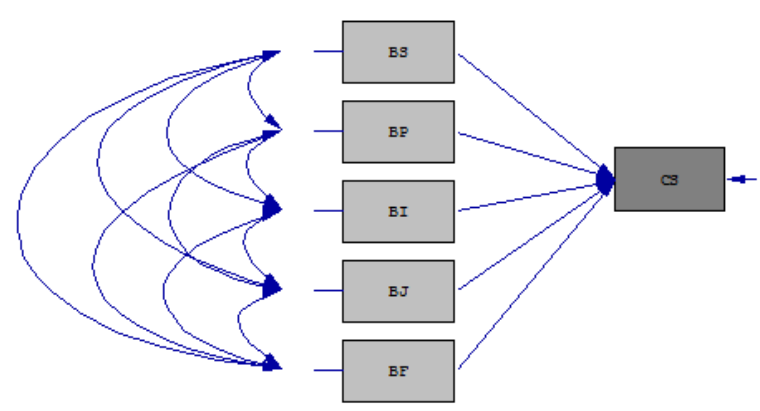

Gambar 1.Hubungan Kausal Antara

Variabel $X_{1}, X_{2}, X_{3}, X_{4}, X_{5}$, dan $Y$

Keterangan :

$\mathrm{BS}=$ Brand Salience $\left(\mathrm{X}_{1}\right)$

$\mathrm{BP}=$ Brand Performance $\left(\mathrm{X}_{2}\right)$

$\mathrm{BI}=$ Brand Imagery $\left(\mathrm{X}_{3}\right)$

$\mathrm{BJ}=$ Brand Judgments $\left(\mathrm{X}_{4}\right)$

$\mathrm{BF}=$ Brand Feelings $\left(\mathrm{X}_{5}\right)$

$\mathrm{CS}=$ Kepuasan Konsumen $(\mathrm{Y})$

\section{PEMBAHASAN}

\section{Hasil Penelitian}

Setelah melakukan trimming dan analisis menggunakan program Lisrel 8.5, terbentuklah persamaan struktural sebagai berikut :

$\mathrm{Y}=0,23 \mathrm{X}_{2}+0,23 \mathrm{X}_{3}+0,45 \mathrm{X}_{5}, \mathrm{R}^{2}=0,53$

$$
\text { Pengujian hipotesis secara }
$$

keseluruhan dengan bentuk sebagai berikut

$\mathrm{H}_{0}: \mathrm{R}_{\mathrm{Y}\left(\mathrm{X}_{2} \mathrm{X}_{3} \mathrm{X}_{5}\right)}=0$; artinya tidak terdapat pengaruh Brand

Performance, Brand Imagery, Brand Feelings secara bersama-sama terhadap Kepuasan Konsumen

$$
\begin{aligned}
& \mathrm{H}_{1}: \mathrm{R}_{\mathrm{Y}\left(\mathrm{X}_{2} \mathrm{X}_{3} \mathrm{X}_{5}\right)} \neq 0 ; \text { artinya terdapat } \\
& \text { pengaruh Brand } \\
& \text { Performance, Brand } \\
& \text { Imagery, Brand } \\
& \text { Feelings secara } \\
& \text { bersama-sama } \\
& \text { terhadap Kepuasan } \\
& \text { Konsumen }
\end{aligned}
$$

Rumus statistik uji yang digunakan untuk menguji hipotesis diatas adalah rumus statistik uji F, yaitu sebagai berikut:

$$
F=\frac{(n-k-1) R_{X_{u}\left(X_{1} X_{2} \cdots X_{k}\right)}^{2}}{k\left(1-R_{X_{u}\left(X_{1} X_{2} \cdots X_{k}\right)}^{2}\right)}
$$

Statistik uji $F$ diatas mengikuti tabel distribusi F-Snedecor dengan derajat bebas $\mathrm{k}$ dan $\mathrm{n}-\mathrm{k}-1$. Kriteria uji yang digunakan adalah tolak $\mathrm{H}_{0} \mathrm{jika} \mathrm{F}_{\text {hitung }}>$ $\mathrm{F}_{\text {tabel }(\alpha ; \mathrm{k} ; \mathrm{n}-\mathrm{k}-1)}$.

Nilai $F$ hitung untuk persamaan struktural yang pertama, yaitu sebagai berikut :

$$
F=\frac{(150-3-1)(0,53)}{3(1-0,53)}=54,88
$$

Dengan menggunakan tael distribusi F, diperoleh $\quad \mathrm{F}_{\text {tabel }(0,05 / 2 ; 3 ; 150)}=3,23$. Karena $\mathrm{F}>\mathrm{F}_{\text {tabel }}$, maka $H_{0}$ ditolak. Brand Performance, Brand Imagery, Brand Feelings secara bersama-sama memiliki pengaruh terhadap kepuasan konsumen, sehingga dapat diteruskan pada pengujian individu.

Statistik uji yang digunakan pada pengujian secara individual masing- 
masing sub-variabel adalah statistik uji t, dengan menggunakan rumus statistik uji sebagai berikut:

$$
\mathrm{t}=\frac{\mathrm{P}_{\mathrm{X}_{\mathrm{u}} \mathrm{X}_{\mathrm{i}}}}{\sqrt{\frac{\left(1-\mathrm{R}_{\mathrm{X}_{\mathrm{u}}\left(\mathrm{X}_{1} \mathrm{X}_{2} \ldots \mathrm{X}_{\mathrm{k}}\right) \cdot \mathrm{C}_{\mathrm{ii}}}^{(\mathrm{n}-\mathrm{k}-1)}\right.}{1,2, \ldots, \mathrm{k}}}} \quad ; \mathrm{u} \text { dan } \mathrm{i}=
$$

Statistik uji diatas mengikuti distribusi $\mathrm{t}$ dengan derajat bebas $=\mathrm{n}-\mathrm{k}-1$ dan kriteria uji yang digunakan adalah tolak $\mathrm{H}_{0}$ jika $t_{\text {hitung }}>t_{\text {tabel }(\alpha ; n-k-1)}$.

Dengan menggunakan program statistik Lisrel 8.5, berikut koefisien jalur beserta pengujiannya.

\section{Tabel 1}

\section{Pengujian Pengaruh Ekuitas Merek \\ Berbasis Pelanggan Terhadap} Kepuasan Konsumen Secara Individual

\begin{tabular}{|c|c|c|c|c|}
\hline $\begin{array}{c}\text { Varia } \\
\text { bel }\end{array}$ & $\begin{array}{c}\text { Koefisi } \\
\text { en } \\
\text { Jalur }\end{array}$ & $\begin{array}{c}\mathbf{t}- \\
\text { hitu } \\
\text { ng }\end{array}$ & $\begin{array}{c}\text { t- } \\
\text { tab } \\
\text { el }\end{array}$ & $\begin{array}{c}\text { Kesimpu } \\
\text { lan }\end{array}$ \\
\hline $\mathrm{P}_{\mathrm{YX}_{2}}$ & 0,23 & 3,20 & $\begin{array}{c}H_{0} \\
8\end{array}$ & $\begin{array}{c}\text { ditolak, } \\
\text { terdapat } \\
\text { pengaruh } \\
\text { nyata }\end{array}$ \\
\hline $\mathrm{P}_{\mathrm{YX}_{3}}$ & 0,23 & 3,42 & 1,9 & $\begin{array}{c}H_{0} \\
\text { ditolak, } \\
\text { terdapat } \\
\text { pengaruh } \\
\text { nyata }\end{array}$ \\
\hline $\mathrm{P}_{\mathrm{YX}_{5}}$ & 0,45 & 7,06 & 1,9 & $H_{0}$ \\
\hline
\end{tabular}

\begin{tabular}{|c|c|c|c|c|}
\hline $\begin{array}{c}\text { Varia } \\
\text { bel }\end{array}$ & $\begin{array}{c}\text { Koefisi } \\
\text { en } \\
\text { Jalur }\end{array}$ & $\begin{array}{c}\text { t- } \\
\text { hitu } \\
\text { ng }\end{array}$ & $\begin{array}{c}\text { t- } \\
\text { tab } \\
\text { el }\end{array}$ & Kesimpu \\
lan \\
& & & 8 & ditolak, \\
& & & & $\begin{array}{c}\text { terdapat } \\
\text { pengaruh } \\
\text { nyata }\end{array}$ \\
& & & & tabel \\
\hline
\end{tabular}

distribusi $\mathrm{t}$ diperoleh $\mathrm{t}_{(0,05 / 2 ; 150)}=1,9799$. Berdasarkan hasil perhitungan pada Tabel 1, dapat terlihat bahwa semua $t_{\text {hitung }}>$ $t_{\text {tabel }}$. Oleh karena itu, Brand Performance, Brand Imagery, dan Brand Feelings diindikasikan memiliki pengaruh terhadap kepuasan konsumen. Kemudian dengan menngunakan rumus $\varepsilon_{2}=1-$ $\mathrm{R}^{2}=1-0,53=0,47, \quad$ yang berarti pengaruh variabel lain diluar model terhadap kepuasan pelanggan sebesar 0,47 .

Dari 5 variabel ekuitas merek berbasis pelanggan yang diuji dalam penelitian ini, ternyata hanya Brand Performance $\left(\mathrm{X}_{2}\right)$, Brand Imagery $\left(\mathrm{X}_{3}\right)$, Brand Feelings $\left(\mathrm{X}_{5}\right)$ yang diindikasikan berpengaruh nyata terhadap Kepuasan Konsumen (Y).

Selanjutnya dilakukan uji keberartian koefisien korelasi antar variabel Brand Performance $\left(\mathrm{X}_{2}\right)$, Brand Imagery $\left(\mathrm{X}_{3}\right)$, Brand Feelings $\left(\mathrm{X}_{5}\right)$ dengan hipotesis sebagai berikut : 
$H_{0}: \rho_{\mathrm{X}_{\mathrm{i}} \mathrm{X}_{\mathrm{j}}}=0$; tidak terdapat hubungan nyata

$H_{1}: \rho_{\mathrm{X}_{\mathrm{i}} \mathrm{X}_{\mathrm{j}}} \neq 0 ;$ terdapat hubungan nyata

Statistik uji yang digunakan pada pengujian keberartian koefisien korelasi antar variabel adalah statistik uji t, dengan menggunakan rumus statistik uji sebagai berikut:

$$
t=r \sqrt{\frac{n-2}{1-r^{2}}}
$$

Statistik uji diatas mengikuti distribusi $\mathrm{t}$ dengan derajat bebas $=\mathrm{n}-\mathrm{k}-1$ dan kriteria uji yang digunakan adalah tolak $\mathrm{H}_{0}$ jika $t_{\text {hitung }}>t_{\text {tabel }(\alpha ; n-k-1)}$.

Dengan menggunakan program statistik Lisrel 8.5, diperoleh koefisien korelasi beserta pengujiannya yaitu sebagai berikut:

Tabel 2

Pengujian Hubungan Kausal antar Variabel Eksogen

\begin{tabular}{|c|c|c|c|c|}
\hline $\begin{array}{c}\text { Varia } \\
\text { bel }\end{array}$ & $\begin{array}{c}\text { Koefisi } \\
\text { en } \\
\text { Korela } \\
\mathbf{s i}\end{array}$ & $\begin{array}{c}\mathbf{t}- \\
\text { hitu } \\
\mathbf{n g}\end{array}$ & $\begin{array}{c}\mathbf{t}- \\
\text { tab } \\
\text { el }\end{array}$ & $\begin{array}{c}\text { Kesimpu } \\
\text { lan }\end{array}$ \\
\hline $\mathrm{r}_{\mathrm{X}_{2} \mathrm{X}_{3}}$ & 0,54 & 5,76 & $\begin{array}{c}1.9 \\
8\end{array}$ & $\begin{array}{c}H_{0} \\
\text { ditolak, } \\
\text { terdapat } \\
\text { hubungan } \\
\text { nyata }\end{array}$ \\
\hline $\mathrm{r}_{\mathrm{X}_{2} \mathrm{X}_{5}}$ & 0,43 & 4,79 & $\begin{array}{c}1.9 \\
8\end{array}$ & $\begin{array}{c}H_{0} \\
\text { ditolak, } \\
\text { terdapat }\end{array}$ \\
\hline
\end{tabular}

\begin{tabular}{|c|c|c|c|c|}
\hline $\begin{array}{c}\text { Varia } \\
\text { bel }\end{array}$ & $\begin{array}{c}\text { Koefisi } \\
\text { en } \\
\text { Korela } \\
\text { si }\end{array}$ & $\begin{array}{c}\text { t- } \\
\text { hitu } \\
\text { ng }\end{array}$ & $\begin{array}{c}\mathbf{t}- \\
\text { tab } \\
\text { el }\end{array}$ & $\begin{array}{c}\text { Kesimpu } \\
\text { lan }\end{array}$ \\
\hline & & & & $\begin{array}{c}\text { hubungan } \\
\text { nyata }\end{array}$ \\
$\mathrm{r}_{\mathrm{X}_{3} \mathrm{X}_{5}}$ & 0,35 & 4,02 & 1.9 & $\begin{array}{c}H_{0} \\
\text { ditolak, } \\
\text { terdapat } \\
\text { hubungan } \\
\text { nyata }\end{array}$ \\
\hline
\end{tabular}

Dengan menggunakan tabel distribusi $t$ diperoleh $\mathrm{t}_{(0,05 / 2 ; 116)}=1,9799$, dan seluruh t-hitung pada Tabel 2 lebih besar dari t-tabel. Oleh karena itu, dapat disimpulkan bahwa terdapat hubungan nyata antara Brand Performance $\left(\mathrm{X}_{2}\right)$, Brand Imagery $\left(\mathrm{X}_{3}\right)$, dan Brand Feelings $\left(\mathrm{X}_{5}\right)$.

Diagram jalur yang akhirnya terbentuk adalah sebagai berikut :

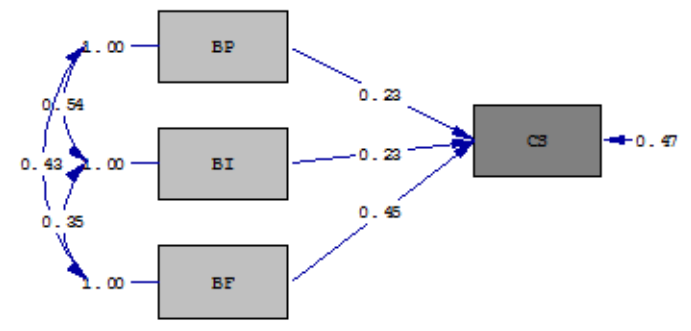

Gambar 2. Diagram Jalur Akhir Antara Ekuitas Merek Berbasis Pelanggan, dan Kepuasan Konsumen 
Berdasarkan hasil perhitunganperhitungan sebelumnya, maka dapat terungkap bahwa kontribusi brand performance terhadap kepuasan konsumen dapat dilihat pada tabel di bawah ini :

Tabel 3

Pengaruh Langsung dan Tidak Langsung dari Brand Performance $\left(\mathrm{X}_{2}\right)$ Terhadap Kepuasan Konsumen (Y) \begin{tabular}{|l|l|}
\hline Interpretasi Analisis Jalur Pengaruh \\
\hline
\end{tabular}

\begin{tabular}{|l|c|c|}
\hline Pengaruh langsung ke Y & 0,0529 & $5,29 \%$ \\
\hline Pengaruh tidak langsung & & \\
\hline
\end{tabular}

\begin{tabular}{|c|c|} 
melalui $\mathrm{X}_{3}$ ke $\mathrm{Y}$ & 0,028566 \\
\hline $\begin{array}{c}\text { Pengaruh tidak langsung } \\
\text { melalui } \mathrm{X}_{5} \text { ke } \mathrm{Y}\end{array}$ & 0,044505 \\
\hline \multicolumn{2}{|c|}{ Total }
\end{tabular}

Dari Tabel 5.3, dapat diketahui bahwa pengaruh brand performance terhadap kepuasan konsumen lebih besar secara tidak langsung (7,31\%) dibandingkan berpengaruh secara langsung $(5,29 \%)$. Hal ini berarti pengaruh brand performance terhadap kepuasan konsumen tidak besar, namun ketika brand performance diaplikasikan kepada brand imagery dan brand feelings maka pengaruhnya akan meningkat. Secara keseluruhan kontribusi brand perforn Interpretasi Analisis Jalur terhadap kepuasan konsumen mencapłengaruh langsung ke Y $12,60 \%$.

Kontribusi brand imagery terhadap Pengaruh tidak langsung kepuasan konsumen masih lebih besar 4,45\% 8 engaruh secara tidak langsung sebesar $6,48 \%$, dibandingkan pengaruh secara 12,60p/angsung sebesar 5,29\%. Hal ini berarti pengaruh brand imagery terhadap kepuasan konsumen tidak besar, namun ketika brand imagery diaplikasikan kepada brand performance dan brand feelings maka pengaruhnya akan meningkat. Secara keseluruhan kontribusi brand imagery terhadap kepuasan konsumen mencapai $11,77 \%$.

Tabel 5

Pengaruh Langsung dan Tidak Langsung dari Brand Feelings $\left(\mathrm{X}_{5}\right)$ Terhadap Kepuasan Pelanggan (Y) kepuasan konsumen dapat dilihat tabel di bawah ini :

Tabel 4

\begin{tabular}{|c|c|c|}
\hline $\begin{array}{c}\text { paçengaruh tidak langsung } \\
\text { melalui } \mathrm{X}_{3} \text { ke } \mathrm{Y}\end{array}$ & 0,036225 & $3,62 \%$ \\
\hline Total & & $28,32 \%$ \\
\hline
\end{tabular}


Brand Feelings akan lebih berpengaruh terhadap kepuasan konsumen secara langsung yaitu sebesar 20,25\%, dibandingkan secara tidak langsung sebesar $8,07 \%$. Secara keseluruhan kontribusi brand feelings terhadap kepuasan konsumen mencapai $28,32 \%$.

Berdasarkan Tabel 6, terlihat bahwa Brand Performance, Brand Imagery, dan Brand Feelings memberikan kontribusi positif terhadap kepuasan konsumen. Dibandingkan Brand Performance dan Brand Imagery, Brand Feelings paling banyak memberikan kontribusi terhadap kepuasan konsumen sebesar $28,32 \%$.

\section{Tabel 6}

Pengaruh Total dari Brand Performance, Brand Imagery, dan Brand Feelings terhadap Kepuasan Konsumen

\begin{tabular}{|c|c|}
\hline Variabel & Pengaruh (\%) \\
\hline $\begin{array}{c}\text { Brand Performance } \\
\left(\mathrm{X}_{2}\right)\end{array}$ & $12,60 \%$ \\
\hline Brand Imagery $\left(\mathrm{X}_{3}\right)$ & $11,77 \%$ \\
\hline Brand Feelings $\left(\mathrm{X}_{5}\right)$ & $28,32 \%$ \\
\hline
\end{tabular}

\section{SIMPULAN}

Para konsumen mobil LCGC sudah banyak mengetahui dan mengenal merekmerek mobil LCGC selain yang digunakannya. Mobil LCGC dikategorikan cukup mampu dalam memenuhi kebutuhan fungsional konsumen. Selain itu, mobil
LCGC sudah mampu memenuhi kebutuhan psikologis atau sosial konsumen. Persepsi konsumen terhadap mobil LCGC sudah baik yaitu sebagai mobil yang paling murah dan paling hemat bahan bakar dibandingkan dengan mobil jenis lain. Reaksi dan respon emosional para pengendara mobil LCGC sudah baik dimana mereka merasa nyaman menggunakan mobil LCGC.

Para pengguna Mobil LCGC sudah puas karena sudah sesuai dengan harapan pelanggan, sehingga mereka tidak menyesal menggunakannya. Mereka yakin hanya akan memilih mobil jenis LCGC, namun ragu memilih merek lain. Hal itu mungkin dikarenakan keterbatasan ekonomi atau keyakinan mereka terhadap merek lain. Mereka pun memutuskan akan melanjutkan menggunakan mobil LCGC yang mereka miliki sekarang, dan akan merekomendasikan kepada orang lain.

Dari 5 variabel ekuitas merek berbasis pelanggan yang diuji dalam penelitian ini, ternyata hanya Brand Performance, Brand Imagery, Brand Feelings yang diindikasikan berpengaruh nyata terhadap Kepuasan Konsumen. Brand Performance, Brand Imagery, Brand Feelings berpengaruh positif terhadap kepuasan konsumen. Di antara sub variabel ekuitas merek berbasis pelanggan, Brand Feelings yang lebih banyak memberikan kontribusi terhadap kepuasan 
konsumen dibandingkan dengan Brand Performance dan Brand Imagery.

Perusahaan yang memproduksi jenis mobil LCGC yang memasarkan produknya di kota Tasikmalaya, Brand Feelings sangat perlu sering dimonitor dan ditingkatkan karena yang sangat berpengaruh terhadap kepuasan konsumen. Namun brand performance dan brand imagery juga masih perlu dimonitor kinerjanya, karena masih memiliki pengaruh terhadap kepuasan konsumen. Oleh karena itu, pihak perusahaan dapat memfokuskan pada peningkatan brand feelings, brand performance dan brand imagery sebagai faktor utama pembentuk kepuasan konsumen mobil jenis LCGC di Kota Tasikmalaya.

Model penelitian yang diajukan pada penelitian ini ternyata memiliki keterbatasan baik dalam pengujian instrumen maupun dalam pengujian hipotesis penelitian. Dalam penelitian ini brand resonance tidak dapat dimasukan ke dalam model karena tidak memenuhi kriteria pengujian instrumen. Oleh karena itu arahan bagi penelitian selanjutnya apabila menggunakan variabel yang sama adalah dengan menambahkan atau mengganti instrumen untuk variabel brand resonance. Selain itu untuk variabel brand saliance dan brand judgements juga tidak terbukti memiliki pengaruh terhadap kepuasan konsumen perlu dilakukan penelitian lanjutan dengan pengujian kedua variabel tersebut dengan menggunakan objek penelitian yang berbada untuk mendapatkan hasil yang lebih baik bagi pengujian model penelitian yang sama. Untuk penelitian selanjutnya juga dapat mengembangkan model pengujian pengaruh dari ekuitas merek berbasis pelanggan terhadap variabel lain yang dapat memberikan dampak besar bagi pengembangan keilmuan seperti kepercayaan konsumen, loyalitas konsumen, dan lain sebagainya.

\section{Daftar Pustaka}

Aaker, D.A. (2005). Brand Management \& Strategy. Yogyakarta: Andi.

Aaker, D.A. (1997). Manajemen Ekuitas Merek, Memanfaatkan Nilai dari suatu Merek. Jakarta: PT Gramedia Pustaka Utama.

Aluregowda. (2011). Impact of Brand Equity and Brand Loyalty on Customer Satisfaction", Journal of Research Commerce and Management, Vol. 02 No. 11.

Durianto, Darmadi, Sugiarto dan lie Joko Budiman. (2004). Brand Equity Ten: Stategi memimpin Pasar. Jakarta: PT Gramedia Pustaka Utama.

Ekinci. Y., Dawes. P.L., and Massey, G.R. (2008). An Extended Model of The Antecedents and Consequences of Customer Satisfaction for Hospitality 
Services.European Journal of

Marketing, Vol. 42 No. 1.

Fandy, T. (2006). Manajemen Pemasaran jasa. Jakarta: Bayumedia.

Hair, J. (1995). Multivariate Data Analisis. U.S.A Mexico-Canada: PrenticeHall International INC.

Husain, U. (2002). Riset Pemasaran Dan Prilaku Konsumen. Jakarta: PT. Gramedia Pustaka Utama.

Puspita, Y. H. (2014). Analisis Pengaruh Ekuitas Merek Berbasis Pelanggan Terhadap Minat Beli Produk Sepeda Motor Matic. Skripsi, Universitas katolik Soegijapranata.

Sugiama, G. (2008). Metode Riset Bisnis dan Manajemen. Bandung: Guardaya Intimarta.

Suliyanto. (2007). Pelatihan Analisis Data. Purwokerto: Laboratorium
Manajemen Fakultas Ekonomi Kampus Unsoed Grendeng.

Puspita, Y. H. (2014). Analisis Pengaruh Ekuitas Merek Berbasis Pelanggan Terhadap Minat Beli Produk Sepeda Motor Matic. Skripsi, Universitas katolik Soegijapranata.

Wang, W.T., \& Li, H. M. (2012). Factors influencing mobile services adoption: a brand-equity perspective. Internet Research, Vol. 22 No. 2, 142-179. 